\title{
Fungal infections from the diabetic foot ulcers in AL-Samawah city
}

Received : 7/12/2017

Accepted : 18/1/2018

\author{
Mouna Akeel Hamed Al-Oebady \\ College of Science, Al-Muthanna University \\ Email: mouna.aloebady@yahoo.com
}

\begin{abstract}
A total of 150 samples from diabetic foot ulcers at many ages for both genders (86 male and 64 female) were collected from patients suffering from diabetic wounds infections who attending the Samawah Hospital of AL-Muthanna province during the period from June 2015 to May 2016.

The fungal infections of diabetic foot were caused by Candida species. Candida albicans was the most common causative agent 46\103( 44.66\%), followed by C. tropicalis, C. dublinensis, C. krusei, C.parapsilosis and C. guillermondi were 23 (22.33\%), 15(14.56\%), 9(8.73\%), 6(5.82\%) and 4(3.88\%) respectively. The highest incidence was Aspergillus spp $23 \backslash 47$ (48.93\%). The other molds isolated were Penicillium marneffei 14(29.78\%), Fusarium solani 8 (17.02\%), and Basidiobolus ranarum 2 $(4.25 \%)$.
\end{abstract}

Key words: Fungal isolations ; diabetics; Candida sp; foot ulcers.

\section{Introduction}

Diabetes mellitus is a chronic metabolic disease having relative or complete insulin deficiency, leading to gross defects in glucose, fat and protein metabolism $(1,2)$. Diabetes is an important predisposing factor for fungal infections and causes significant morbidity and mortality. The greater frequency of infections in diabetic patients is caused by hyperglycemic environment which attributes to defect in both cell-mediated immunity and humoral immunity $(3,4)$. Fluctuating blood sugar and hypoxia from poor circulation may impair the ability of white blood cells to destroy pathogenic bacteria and fungi increasing infection risk (5). Patients with diabetes represent a unique group of individuals who appear more prone to develop infections than others. Several mechanisms have been proposed to explain the association between diabetes and infections. However, few conclusive studies exist and a considerable debate is going on regarding the evidence for this predisposition. Diabetes mellitus is a chronic disorder that affects a large segment of the human population and is a major public health problem. Diabetes and foot problems are almost synchronous $(6,7)$.

Diabetic foot infections frequently result in morbidity، hospitalization and amputations $(8,9,10)$. 


\section{Aims and Objectives}

1. To study the prevalence of fungal infection in diabetic foot ulcers.

\section{Materials and methods}

\section{Collection of samples}

The samples were collected from the Samawah Hospital during the period from June 2015 to May 2016. The total number of cases studied were 150 from diabetic wound patients. The isolates were taken from skin foot infections of the different ages for both gender.

\section{Culture of samples}

The sample was collected from the depth of the wound. Direct microscopic examination was carried out using $10 \%$ potassium hydroxide $(\mathrm{KOH})$ (11). For the isolation of both moulds and yeasts, the sample was inoculated on two sets of Sabouraud's dextrose agar slants with chloramphenicol. One slant was incubated at room temperature and other at $37 \mathrm{C}$ for one month (12). The media were observed for growth daily for the first week and

\section{Results and Discussion}

In this study, a total of 150 wound swabs specimens were collected and examined from patients who suffered from diabetic infections. The total wound swabs with diabetic according to the gender groups were $(65.4 \%$ and $34.6 \%)$ for male and female respectively. The majority for
2. To study the spectrum of fungal strains isolated from the wounds.

3. To compare our findings with those of previous studies.

Tissue specimens were obtained from the depth of the wound (taking aseptic precautions) after debridement. Samples were transferred to the laboratory within an hour in sterile containers.

twice a week for the subsequent period. Further the culture was identified by macroscopic and microscopic morphology such as lactophenol cotton blue, slide culture. Further for isolation of Candida, growth from Sabouraud's dextrose agar inoculated onto corn-meal agar and identified by germ tube formation, urease test, sugar fermentation Chromagar Candida and Api Candida used in the diagnosis of Candida species (13).

male ( Table 1 ). Which is similar to the results of a study by $(14,15)$. This indicates males with diabetes are more prone to develop foot ulcer and infection than females and it may be attributed to more outdoor activities, poor foot care, and differences in lifestyle. 
(Table 1) :Numbers of diabetic patients according to gender.

\begin{tabular}{|c|c|c|}
\hline Samples & Diabetic patients & $\%$ \\
\hline Male & 86 & 65.4 \\
\hline Female & 64 & 34.6 \\
\hline Total & 150 & 100 \\
\hline
\end{tabular}

The fungal infections of diabetic foot infections were caused by Candida species . Candida albicans was the most common causative agent 46\103( 44.66\%), followed by $C$. tropicalis, C. dublinensis, C. krusei, C.parapsilosis and $C$. guillermondi were 23 (22.33\%), $15(14.56 \%), \quad 9(8.73 \%), \quad 6(5.82 \%)$ and 4(3.88 respectively (table 2 ).

The study conducted by (16) showed the presence of various fungal pathogens in diabetic foot ulcer tissues, among which
Candida species preponderated. (17) has also reported the association of Candida spp with protracted ulceration in diabetic feet which improved the following systemic antifungal therapy. This is in agreement with the findings of the present study showing that among the fungal pathogens isolated from deep tissues were Candida spp. The investigators could also identify Candida species like $C$. parapsilosis, C. albicans, C. tropicalis and C. glabrata from the infected tissues.

\section{( Table 2): Candida species isolated from diabetic foot infections.}

\begin{tabular}{|l|l|l|}
\hline Candida species & Number & $\%$ \\
\hline Candida albicans & 46 & 44.66 \\
\hline Candida tropicalis & 23 & 22.33 \\
\hline Candida dublinensis & 15 & 14.56 \\
\hline Candida krusei & 9 & 8.73 \\
\hline Candida parapsilosis & 6 & 5.82 \\
\hline Candida guillermondi & 4 & 3.88 \\
\hline Total & 103 & 100 \\
\hline
\end{tabular}

The mold species were identified on the basis of their microscopic and macroscopic appearance as described by (18) . The highest incidence was
Aspergillus spp $23 \backslash 47$ (48.93\%) . The other molds isolated were Penicillium marneffei 14(29.78\%), Fusarium solani 8 (17.02 \%), and Basidiobolus ranarum 2 


\section{AL-Qadisiyah Journal of pure Science Vol.23 No. 1 Year 2018}

(4.25\%). P. marneffei was unique due to its dimorphic nature at different temperatures and also its rare occurrence.

The presence of Aspergillus spp and $F$. solani has been reported by some workers on diabetic foot ulcer (19) . In our study, among other mold species we also isolated Aspergillus spp and $F$. solani from the infected foot. In other study (18) have reported a case of simultaneous aspergillosis and mucormycosis complicating diabetic foot gangrene $P$. marneffei has been rarely reported in India. P. marneffei infections have been documented in HIV-infected individuals

(Table 3): Mold species isolated from diabetic foot infections.

\begin{tabular}{|l|l|l|}
\hline Mold species & No. & $\%$ \\
\hline Aspergillus spp & 23 & 48.93 \\
\hline Penicillium marneffei & 14 & 29.78 \\
\hline Fusarium solani & 8 & 17.02 \\
\hline Basidiobolus ranarum & 2 & 4.25 \\
\hline Total & 47 & 100 \\
\hline
\end{tabular}

\section{Conclusion}

Due to hyperglycemic environment and suppressed immunity, diabetic patients are more prone to infections. Fungal

\section{References}

1.Wild S, Roglic G, Green A.(2004). Global prevalence of diabetes: estimates from the northeastern part of India (19) . This infection has been predominantly reported from Southeast Asia, where it has been found to be the third most common illness that specifies the Acquired Immuno Deficiency Syndrome ( AIDS) (20). P. marneffei is pathogennic particularly in patients with AIDS and its isolation from blood is considered an HIV marker in endemic areas (11). The present study signifies the need of a mycological evaluatuion of non-healing diabetic foot and prudent antifungal treatment based on the culture results rather than depending on broad spectrum antifungal for cure. 


\section{AL-Qadisiyah Journal of pure Science Vol.23 No. 1 Year 2018}

2. Geerlings SE, Hoepelman AI.(1999). Immune dysfunction in patients with diabetes mellitus. FEMS Immunol Med Microbiol , Dec;26(3-4):259-65.

3. Stadelman WK, Digenis AG and Tobin GR.(1998). Impediments to wound healing. Am J Surg ;176:395-475.

4. Shahi S, Kumar A, Kumar S, Singh S, Gupta S, Singh T (2012). Prevalence of diabetic foot ulcer and associated risk factors in diabetic patients from North India. J Diabet Foot Complications 2012;4:83-91.

5 .Abilash S, Kannan N, Rajan K, Pramodhini MR. Clinical study on the prevalence of fungal infections in diabetic foot. Int J Curr Res Rev 2015;7:8-13.

6. Chincholikar, D. A, R. B. Pal,( 2002). Indian J. Pathol. Microbiol., 45 (1), 15-22.

7.Zubair M, Malik A, Ahmad J. Incidence, risk factors for amputation among patients with diabetic foot ulcer in a North Indian tertiary care hospital. Foot(Edinb) 2012;22:24-30.

8 .Mendes JJ, Marques-Costa A, Vilela C, Neves J, Candeias N`Cavaco-Silva P, et al. Clinical and bacteriological survey of diabetic foot infections in Lisbon. Diabetes Res Clin Pract 2012;95:153-61.

9. Heald, A. H, D. J. Ohalloran, K. Richards, F. Webb, S. Jenkis, S. Hollis, D.
W. Denning, R. J. Young, (2001). Diab. Med., 18 (7), 567-572.

10. Bader, M., A. K. Jafri, T. Krueger, V. Kumar,( 2003). Scand. J. Infect. Dis.., 35 (11-12), 895-896.

11 .Abilash S, Kannan N, Rajan K, Pramodhini MR. Clinical study on the prevalence of fungal infections in diabetic foot. Int J Curr Res Rev 2015;7:8-13.

12 .Fata S, Hadi M, Modaghegh S, Faizi R. Mycotic infections in diabetic foot ulcers in Emam Reza hospital, Mashhad, 2006-2008. Jundishapur J Microbiol 2011;4:11-6.

13 .Wijesuriya TM, Weerasekera MM, Kottahachchi J, Ranasinghe KN، Dissanayake MS, Prathapan S, et al. Proportion of lower limb fungal foot infections in patients with Type 2 diabetes at a tertiary care hospital in Sri Lanka. Indian J Endocrinol Metab 2014;18:63-9.

14. Reyes, C. V., J. W. Rippon, (1984). Hum. Pathol., 15 (1), 89-91.

15. Ranjana, K. H., K. Priyokumar, T. J. Singh, C. C. Gupta, L. Sharmila, P. N. Singh, (2002). J. Infect., 45, 268-271.

16. Forbes, B. A., D. F. Sahm 1, A. S. Weissfeld،(2002). Bailey and Scotts diagnostics microbiology، 11th edn, London: Mosby. 
AL-Qadisiyah Journal of pure Science Vol.23 No. 1 Year 2018

17 .Wijesuriya TM, Weerasekera MM, Kottahachchi J, Ranasinghe KN، Dissanayake MS, Prathapan S, et al. Proportion of lower limb fungal foot infections in patients with Type 2 diabetes at a tertiary care hospital in Sri Lanka. Indian J Endocrinol Metab 2014;18:63-9.

18. Silva, A. P., I. M. Miranda, C. Lisboa, C. Pina-Vaz, and A. G. Rodrigues.2009.Prevalence, distribution, and antifungal susceptibility profiles of Candida parapsilosis, C. orthopsilosis, and C. metapsilosis in a tertiary care hospital. J. Clin. Microbiol. 47:2392-2397.

19. Cardenes-Perera, C. D., A. TorresLana, R. Alonso-Vargas, M. D. Moragues-
Tosantas, J. Ponton-San Emeterio, G. Quindos-Andres, and M. P. ArevaloMorales. 2004. Evaluation of API ID 32C and VITEK-2 to identify Candida dubliniensis. Diagn. Microbiol. Infect. Dis. 50:219-221.

20. Tulumoglu, S., E. Kariptas, and B. Erdem. 2009. Identification and antifungal susceptibility of Candida isolates from various clinical specimens in Doctor Behcet Uz Hospital. Anatol. J. Clin. Invest. 3:170-173. 